\title{
Reliability of daily step activity monitoring in adults with incomplete spinal cord injury
}

\author{
Saori Ishikawa, MS, ATC, CSCS; ${ }^{1 *}$ Sandy L. Stevens, PhD; ${ }^{1-2}$ Minsoo Kang, PhD; ${ }^{1}$ Don W. Morgan, PhD $^{\mathbf{1}}$ \\ ${ }^{1}$ Department of Health and Human Performance, Middle Tennessee State University, Murfreesboro, TN; ${ }^{2}$ Department \\ of Occupational Therapy, Tennessee State University, Nashville, TN
}

\begin{abstract}
We determined the number of days of step activity monitoring required to establish stable measures of walking activity in adults with incomplete spinal cord injury (iSCI). Eleven individuals with iSCI (mean age $49+/-14$ years) wore a StepWatch Activity Monitor during waking hours for 7 consecutive days. We used generalizability theory to identify sources of variance in daily step counts and determine the minimum number of days necessary to obtain a reliability coefficient (G-coefficient) greater than or equal to 0.80. Average daily step activity (DSA) was 1,281 +/- 1,594 steps. Participants and days accounted for $70.9 \%$ and $1.3 \%$ of total variance in DSA, respectively, while unidentifiable error accounted for $27.8 \%$ of the total variance in DSA. A minimum of 2 days was required to achieve a $\mathrm{G}$-coefficient greater than or equal to 0.80. An acceptably stable measure of walking activity in adults with iSCI can be obtained by averaging step count values from any 2-day period in a week. Results from this investigation should be useful in evaluating the effect of activitybased programs designed to enhance locomotor function in persons with iSCI.
\end{abstract}

Key words: daily step activity, exercise, generalizability theory, incomplete spinal cord injury, locomotor training, pedometer, physical activity, reliability, stable measure, step activity monitor.

\section{INTRODUCTION}

It is estimated that 12,000 new cases of spinal cord injury (SCI) occur each year in the United States, with $\sim 262,000$ persons having survived their initial injury [1].
SCI often results in loss of motor, sensory, and autonomic function depending on the level of the lesion and degree of impairment [2]. Because sedentary living in persons with SCI poses a greater risk of cardiovascular disease, type 2 diabetes mellitus, dyslipidemia, obesity, and urinary tract infection [3-5], individuals with SCI have been urged to engage in physical activity to improve ambulatory mobility and maintain a healthy lifestyle [6-11]. In this regard, improvements in walking ability, gait velocity, walking endurance, and lower-limb strength have been observed in adults with incomplete SCI (iSCI) following participation in targeted exercise programs [12-17].

Prior to quantifying changes in physical activity status in persons with iSCI resulting from therapeutic interventions, researchers must establish an accurate and reliable method of assessing locomotor activity. Along these lines, a current approach has been to employ step counting devices to document physical activity in persons with

\footnotetext{
Abbreviations: ASIA = American Spinal Injury Association, DSA = daily step activity, D-study = decision study, G-coefficient = reliability coefficient, G-study = generalizability study, G-theory = generalizability theory, iSCI = incomplete spinal cord injury, SAM = StepWatch Activity Monitor, SCI = spinal cord injury.

*Address all correspondence to Saori Ishikawa, MS, ATC, CSCS; Middle Tennessee State University, PO Box 96, Murfreesboro, TN 37132; 774-240-7517.

Email: si2p@mtmail.mtsu.edu

DOI:10.1682/JRRD.2010.09.0190
} 
neurological conditions [18-19]. Tudor-Locke et al. summarized typical step activity values reported in 60 studies of special populations encompassing persons with cardiovascular disease, diabetes, neuromuscular disease, arthritis, and mental retardation/intellectual disability and reported that the step activity monitoring period for individuals with neuromuscular diseases and disability ranged from 2 to 7 days [20]. Relatively little is known, though, concerning the ambulatory activity of persons with iSCI.

Using classical test theory (i.e., intraclass correlation coefficient), Tudor-Locke et al. confirmed that any 3-day combination within a week was sufficient to achieve an acceptable level of reliability ( $r=0.80$ ) with respect to predicting weekly physical activity in nondisabled adults [21]. However, the proportion of variation in a given measurement attributable to different variance sources cannot be readily identified using this traditional statistical approach [22-23]. In contrast, generalizability theory (G-theory) provides a statistical framework that is particularly useful for quantifying the relative contribution of multiple sources of variance to total measurement variation [22-24]. G-theory has been employed in recent studies of physical activity assessment featuring typically developing youth and nondisabled adults [25-27]. To the best of our knowledge, however, G-theory has not been used to document the reliability of step activity monitoring in adults with iSCI.

Against this backdrop, the purpose of our study was to use G-theory to establish the number of days necessary to obtain a stable and representative measure of daily step activity (DSA) in adults with iSCI and to identify sources of variation in step activity in this group. Given the challenges of initiating and maintaining locomotor activity posed by altered neurological and physiological function, we hypothesized that fewer days would be needed to establish a reliable step count profile in persons with iSCI than nondisabled adults.

\section{METHODS}

\section{Participants}

Eleven individuals with iSCI (mean \pm standard deviation age $=49 \pm 14$ years; range $=23$ to 65 years; 8 males, 3 females) participated in this study and provided written informed consent. Descriptive characteristics of the participants are shown in Table 1. The International Standards for Neurological and Functional
Classification of SCI of the American Spinal Injury Association (ASIA) were used to classify study participants according to their level of neuromuscular function. All participants were medically stable and classified as ASIA Class C (incomplete: motor function is preserved below the neurological level, and more than half of key muscles below the neurological level have a muscle grade $<3 ; n=9$ ) or Class D (incomplete: motor function is preserved below the neurological level, and at least half of key muscles below the neurological level have a muscle grade of $\geq 3 ; n=2$ ). Inclusion criteria for the study included the following: (1) older than 21 years, (2) able to complete a 10-meter walk with or without an assistive device, (3) at least 1 year postinjury to ensure the absence of spontaneous recovery from SCI, (4) free from comorbidity or degenerative disease, (5) physician's approval to engage in physical activity, and (6) availability of transportation to the testing site.

\section{Procedures}

A StepWatch Activity Monitor (SAM, Orthocare Innovations; Oklahoma City, Oklahoma) was used to measure step activity counts. The SAM is a small, lightweight accelerometer that was developed in response to concerns regarding the accuracy and reliability of existing activity monitors when used by persons with gait dysfunction [28]. The SAM has been shown to demonstrate 95 percent accuracy and yield stable output during repeated testing (correlation range $=0.84$ to 0.98 ) in persons with normal gait patterns [29]. In addition, Bowden and Behrman compared step counts obtained from the SAM to actual step counts registered during 10-meter and 6-minute walks and reported that the SAM displayed 97 percent accuracy among individuals with SCI [30]. The SAM, which is worn proximal to the malleolus on the lateral border of the ankle, is designed to detect and register step counts for a variety of walking styles, ranging from a slow shuffle to a fast run. Participants who wore an orthotic device on the right ankle were instructed to wear the SAM on the left ankle to increase the likelihood of registering valid step activity [31]. Step counts were recorded in 1-minute epochs during waking hours, and the SAM automatically reset at the end of each day.

Each participant wore a SAM that was randomly chosen from a set of three fully operational devices. Participants were instructed to wear the SAM during waking hours for 7 consecutive days (except when bathing) and maintain a typical physical activity regimen. If participants 
Table 1.

Descriptive characteristics and mean step count activity of study participants $(n=11)$.

\begin{tabular}{|c|c|c|c|c|c|c|c|c|c|c|}
\hline Subject & Sex & $\begin{array}{l}\text { Age } \\
\text { (yr) }\end{array}$ & $\begin{array}{l}\text { Lesion } \\
\text { Level }\end{array}$ & $\begin{array}{l}\text { ASIA } \\
\text { Class }\end{array}$ & $\begin{array}{c}\text { Time } \\
\text { Postinjury } \\
(y r)\end{array}$ & $\begin{array}{c}\text { Mechanism of } \\
\text { Injury }\end{array}$ & $\begin{array}{l}\text { Primary } \\
\text { Mobility }\end{array}$ & $\begin{array}{l}\text { Assistive } \\
\text { Device }\end{array}$ & $\begin{array}{c}\text { Physical } \\
\text { Assistance }\end{array}$ & $\begin{array}{l}\text { Step Counts* } \\
\text { (Mean } \pm \text { SD) }\end{array}$ \\
\hline 1 & $\mathrm{M}$ & 52 & T5-6 & $\mathrm{C}$ & 3 & Trauma & Wheelchair & $\begin{array}{r}\text { Platform } \\
\text { rolling } \\
\text { walker }\end{array}$ & Moderate & $191 \pm 33$ \\
\hline 2 & $\mathrm{M}$ & 62 & $\mathrm{C} 4$ & $\mathrm{D}$ & 2.5 & Trauma & Ambulation & $\begin{array}{c}\text { Bilateral } \\
\text { forearm } \\
\text { crutches }\end{array}$ & Independent & $5,521 \pm 2,057$ \\
\hline 3 & $\mathrm{M}$ & 63 & L2 & $\mathrm{C}$ & 6 & Tumor & Wheelchair & $\begin{array}{c}\text { Bilateral } \\
\text { forearm } \\
\text { crutches }\end{array}$ & Minimal & $60 \pm 25$ \\
\hline 4 & $\mathrm{~F}$ & 51 & C3 & $\mathrm{C}$ & 3 & Trauma & Ambulation & $\begin{array}{r}\text { Platform } \\
\text { rolling } \\
\text { walker }\end{array}$ & Minimal & $1,668 \pm 365$ \\
\hline 6 & $\mathrm{M}$ & 29 & L2 & $\mathrm{C}$ & 29 & Birth & Wheelchair & $\begin{array}{r}\text { Platform } \\
\text { rolling } \\
\text { walker }\end{array}$ & Minimal & $31 \pm 82$ \\
\hline 7 & M & 23 & C6 & $\mathrm{C}$ & 1.5 & Trauma & Wheelchair & $\begin{array}{c}\text { Bilateral } \\
\text { forearm } \\
\text { crutches }\end{array}$ & Independent & $1,846 \pm 792$ \\
\hline 8 & $\mathrm{~F}$ & 64 & $\mathrm{C} 4$ & $\mathrm{C}$ & 1 & Trauma & Ambulation & $\begin{array}{r}\text { Platform } \\
\text { rolling } \\
\text { walker }\end{array}$ & Minimal & $1,920 \pm 2,151$ \\
\hline
\end{tabular}

inadvertently wore the SAM for more than 7 days, only step count data for the first 7 days were used for statistical analysis. Calibration adjustments were made for expected cadence, sensitivity, threshold, and motion characteristics prior to affixing the SAM to either the right or left ankle of each participant with a Velcro wrap. An overground walking test was then performed. If step counts were missed during this initial walking trial or if nonstep activity was registered, further calibration adjustments were made to ensure that all valid step activity was captured. Partici- pants were provided with verbal and written instructions on how to properly wear and position the SAM on the ankle and encouraged to contact the primary investigator if questions arose regarding the step activity monitoring protocol. Upon completion of data collection, the primary investigator contacted participants to record any special events, unexpected fatigue, and/or physical pain that occurred during the weeklong assessment period.

Step count data were downloaded from the SAM and initially screened for accuracy. Because step counts from 
the SAM reflect the step activity of only one leg, we obtained the overall step count of both legs by doubling single-leg step activity.

\section{Data Analysis}

\section{Overview}

For each participant, we calculated DSA for each day of the 7-day monitoring period and averaged the data to determine a mean step count for each participant. Based on G-theory, we performed a generalizability study (Gstudy) and a decision study (D-study) to quantify the relative contribution of different variance components to the total variance in step activity (G-study) and to compute a reliability coefficient (G-coefficient), which would enable the number of days required to obtain a stable measure of step activity to be determined (D-study).

\section{G-Study}

We performed a two-way participant $\times$ day repeatedmeasures analysis of variance to calculate the amount of variance in step counts associated with the participant and day terms as well as the interaction between these terms. The interaction between the participant and day terms also encompassed unidentifiable sources of variation. We calculated the percentage of total variation in DSA attributable to each term and the interaction between terms by dividing the individual variance component estimate by the total variance and multiplying the quotient by 100 .

\section{D-Study}

We conducted a D-study using a fully crossed design (participant $\times$ day) to provide reliability estimates (Gcoefficients) for various combinations of days of step activity monitoring. By conducting a D-study, we were able to determine the number of days necessary to obtain a mean G-coefficient value $>0.80$ for step count measurement [22,24]. As noted by Welk et al., a G-coefficient of 0.80 is an acceptable level of reliability and is interpreted in a similar fashion as an intraclass correlation coefficient of 0.80 [26]. All statistical analyses were performed using Generalized Analysis of Variance software (American College Testing Program; Iowa City, Iowa) [32].

\section{RESULTS}

Mean \pm standard deviation step counts per day for each participant are shown in Table 1. As depicted in Table 2, participants averaged 1,281 \pm 1,594 steps per day over the 7-day monitoring period, with a range of 718 steps on Sunday to 1,642 steps on Thursday.

Findings from the G-study revealed that the participant term accounted for the largest source of variance (70.9\%) in DSA, while the day term contributed to 1.3 percent of the total variance in DSA. The participant and day interaction term, which reflected nonspecific sources of variation, accounted for 27.8 percent of the total variance in DSA. Variance component estimates and the relative magnitude of error for each component term are shown in Table 3.

As presented in the Figure, findings from the Dstudy revealed that various combinations of days of step activity monitoring resulted in G-coefficients ranging from 0.72 to 0.95 and that a minimum of any 2 days of the week yielded a G-coefficient $\geq 0.80$.

Table 2.

Daily and mean step counts for each day of the week $(n=11)$.

\begin{tabular}{lr}
\hline \multicolumn{1}{c}{ Day } & Mean \pm Standard Deviation \\
\hline Saturday & $1,476 \pm 2,531$ \\
Sunday & $718 \pm 1,154$ \\
Monday & $1,127 \pm 1,567$ \\
Tuesday & $919 \pm 1,230$ \\
Wednesday & $1,523 \pm 1,649$ \\
Thursday & $1,642 \pm 1,925$ \\
Friday & $1,563 \pm 2,303$ \\
\hline Overall Mean & $1,281 \pm 1,594$ \\
\hline \hline
\end{tabular}

Table 3.

Variance component estimates and relative magnitude of error for each term.

\begin{tabular}{|c|c|c|}
\hline Term & $\begin{array}{c}\text { Variance Component } \\
\text { Estimates }\end{array}$ & $\begin{array}{l}\text { Relative Magnitude } \\
\text { of Error* (\%) }\end{array}$ \\
\hline$\overline{\mathrm{P}}$ & $2,405,046.00$ & 70.9 \\
\hline $\mathrm{D}$ & $44,005.28$ & 1.3 \\
\hline $\mathrm{P} \times \mathrm{D}$ & $942,204.07$ & 27.8 \\
\hline Total & $3,391,255.40$ & 100 \\
\hline \multicolumn{3}{|c|}{$\begin{array}{l}\text { *Relative magnitude of error for each term was calculated by dividing variance } \\
\text { component estimates by total variance estimate and multiplying quotient by } \\
100 \text {. } \\
\mathrm{D}=\text { day term, } \mathrm{P}=\text { participant term, } \mathrm{P} \times \mathrm{D}=\text { participant } \times \text { day interaction term. }\end{array}$} \\
\hline
\end{tabular}




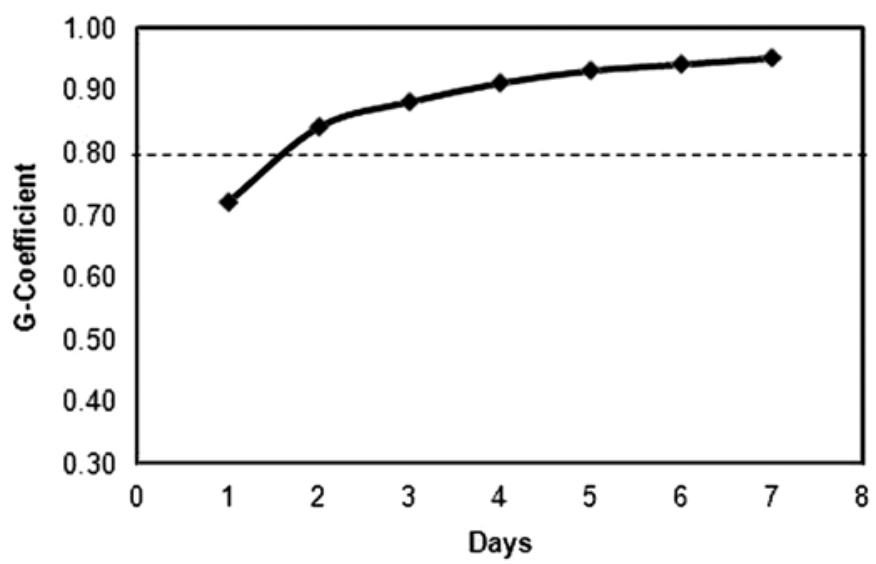

Figure.

Relationship between various combinations of days of step activity monitoring and mean reliability coefficient (G-coefficient) values.

\section{DISCUSSION}

In the current study, G-theory was used to quantify sources of variance in daily step counts and to determine the number of days needed to obtain a reliable measure of walking activity in adults with iSCI. In contrast with classical reliability testing models, G-theory allows for the total variance in a particular variable to be apportioned into known and unknown sources of measurement variance.

Results from our study demonstrated that $\sim 70$ percent of the total variance in DSA was attributable to the participant term, which is the true score variance [25]. More specifically, this finding indicates that the majority of variance in DSA was related to individual differences in daily step counts. Relative to this point, mean DSA varied markedly across participants (31 steps to 5,521 steps). Although speculative, it is possible that this disparity in average step count values may reflect individual differences in both ASIA scale classification and the absence or presence of physical fatigue and pain during the weeklong assessment period. Individuals classified as ASIA Class D, for instance, displayed a higher average step count value (mean $=3,498$ steps) compared with individuals classified as ASIA Class C (mean $=789$ steps). However, because only two participants were classified as ASIA Class D, caution should be applied in interpreting these findings.

The very limited amount of variance in DSA attributable to the day term $(1.3 \%)$ was similar to that noted by
Wickel and Welk [25], who reported a day term of 2.7 percent for establishing the number of days needed to reliably estimate physical activity levels in youth. In the present study, the small error variation linked to the day term is consistent with the relative stability in mean daily step counts observed across the 7 days of step activity monitoring and suggests that increasing the number of days of step count assessment would have only had a minimal effect on reducing total variance in walking activity. We should note that the monitoring period used by Wickel and Welk spanned three seasons (September to May), and the season term accounted for nearly two and a half times the variance associated with their day term [25]. According to Wickel and Welk, seasonal changes linked to weather factors may influence the time available for children to spend outdoors and contribute to a greater proportion of the variance in step activity in youth who are monitored on a long-term basis [25].

The interaction term (participant $\times$ day), which represented unidentified error sources, accounted for nearly 28 percent of the total variance in DSA. In considering possible factors that may have contributed to this source of variation, we minimized the potential influence of activity monitor malfunction by following an established calibration protocol and providing a detailed set of instructions to participants regarding how to properly wear and position the SAM on the ankle. Other factors that may have contributed to the variance in the interaction term include motivation, availability of physical activity resources, ease of navigating the local environment, challenges related to self-care, and physical and mental health status, all of which have been identified as barriers or facilitators of daily physical activity among persons with SCI [33-34]. Recognition of these variables in future studies may help shape our understanding of the myriad internal and external factors that individually or collectively affect physical activity levels in persons who are physically challenged.

As shown in Table 2, a relatively large betweensubject variability in daily step count values was observed compared with the smaller between-day variability in DSA displayed in Table 1. Consequently, a high reliability in walking behavior was recorded for our participant group, leading to the finding that within a week any 2-day combination of step count values can be averaged to obtain a stable value of step activity in adults with iSCI. This result confirms our original hypothesis, which stated that fewer days would be required to derive 
a stable measure of walking activity compared with data published by Tudor-Locke et al. [21], who demonstrated that at least 3 days of monitoring were required to establish reliable step count values in nondisabled adults. In Tudor-Locke et al.'s study [21], an intraclass reliability model was employed, which is similar in approach to Gtheory, insofar as a correlation coefficient of $\geq 0.80$ is deemed an acceptable level of reliability [35]. From a practical standpoint, the need to collect step count data for only 2 days is advantageous, as participant and investigator burdens are reduced and data processing and analysis are simplified. However, as suggested by Kang et al., activity monitoring for relatively short periods may not necessarily yield an accurate picture of physical activity patterns followed for extended time blocks [36]. In addition, although any 2-day combination of step activity monitoring is sufficient to produce a reliable estimate of DSA in adults with iSCI, researchers and clinicians may wish to adopt a more conservative approach by assessing walking activity over a slightly longer time period (e.g., 3 or 4 days) to assure even more generalizable results [24].

As with all studies, some limitations were present in our investigation. Step activity data, for example, were collected on a relatively small sample size with limited variability in ASIA classification. In acknowledging these concerns, we should note that our sample size of 11 participants was comparable to that found in previous studies of persons with iSCI $[30,37]$. Another limitation of the current study was the lack of diary usage to track the occurrence of sickness, physical pain, fatigue, and special occasions that may have influenced the number of steps taken by participants. In an attempt to address this issue, the primary investigator contacted each participant regarding pain, fatigue, sickness, and/or special events experienced during the 7-day monitoring period to confirm the internal validity of the step activity measure. The use of assistive devices can also influence step activity levels. However, because all participants required assistive devices to walk, it is unlikely that this factor biased our findings [12]. Lastly, the extent to which a 2-day period of step activity assessment accurately reflects valid monthly, seasonal, or yearly ambulatory behavior remains unexplored. Based on this collective set of study limitations, additional research should be conducted to more thoroughly quantify variability in locomotor activity in a larger, more functionally diverse sample of individuals with iSCI and to determine whether a brief period of step activity monitoring reflects longer-term ambulatory activity in this group.

\section{CONCLUSIONS}

Results from our study demonstrate that while DSA differs widely among adults with iSCI, a reliable measure of locomotor activity in this population can be obtained by monitoring daily step counts over any combination of 2 days within a week. From a clinical perspective, these findings provide a basis for evaluating the effect of activity-related therapies to enhance walking ability in persons with SCI.

\section{ACKNOWLEDGMENTS}

\section{Author Contributions:}

Study concept and design: M. Kang, D. W. Morgan, S. Ishikawa. Acquisition of data: S. L. Stevens, S. Ishikawa.

Analysis and interpretation of data: M. Kang.

Drafting of manuscript: S. Ishikawa.

Critical revision of manuscript for important intellectual content:

S. Ishikawa, D. W. Morgan.

Statistical analysis: S. Ishikawa, M. Kang.

Administrative, technical, or material support: D. W. Morgan.

Study supervision: D. W. Morgan.

Financial Disclosures: The authors have declared that no competing interests exist.

Funding/Support: This material was unfunded at the time of manuscript publication.

Additional Contributions: The authors gratefully acknowledge Dr. Elizabeth A. Holbrook for her endless support in completing this study.

Institutional Review: The study was approved by the appropriate institutional review board, and all participants provided informed consent.

Participant Follow-Up: The authors do not plan to notify the participants of the publication of this study due to a lack of contact information.

\section{REFERENCES}

1. Spinal cord injury facts and figures at a glance [Internet]. Washington (DC): National Spinal Cord Injury Statistical Center; 2010 [updated 2010 Feb; cited 2010 Jun]. Available from: https://www.nscisc.uab.edu/public content/pdf/ Facts\%202011\%20Feb\%20Final.pdf

2. Jacobs PL, Nash MS. Exercise recommendations for individuals with spinal cord injury. Sports Med. 2004;34(11): 
727-51. [PMID: 15456347]

http://dx.doi.org/10.2165/00007256-200434110-00003

3. Davies DS, McColl MA. Lifestyle risks for three disease outcomes in spinal cord injury. Clin Rehabil. 2002;16(1): 96-108. [PMID: 11837530] http://dx.doi.org/10.1191/0269215502cr443oa

4. Gorgey AS, Gater DR Jr. Prevalence of obesity after spinal cord injury. Top Spinal Cord Inj Rehabil. 2007;12(4):1-7. http://dx.doi.org/10.1310/sci1204-1

5. Jae SY, Heffernan KS, Lee M, Fernhall B. Arterial structure and function in physically active persons with spinal cord injury. J Rehabil Med. 2008;40(7):535-38.

[PMID: 18758670]

http://dx.doi.org/10.2340/16501977-0212

6. Cowell LL, Squires WG, Raven PB. Benefits of aerobic exercise for the paraplegic: A brief review. Med Sci Sports Exerc. 1986;18(5):501-8. [PMID: 3534507] http://dx.doi.org/10.1249/00005768-198610000-00002

7. Davis GM. Exercise capacity of individuals with paraplegia. Med Sci Sports Exerc. 1993;25(4):423-32. [PMID: 8479296]

8. Hoffman MD. Cardiorespiratory fitness and training in quadriplegics and paraplegics. Sports Med. 1986;3(5):312-30. [PMID: 3529281] http://dx.doi.org/10.2165/00007256-198603050-00002

9. Jacobs PL, Nash MS. Modes, benefits, and risks of voluntary and electrically induced exercise in persons with spinal cord injury. J Spinal Cord Med. 2001;24(1):10-18.

[PMID: 11587428]

10. Nash MS. Cardiovascular fitness after spinal cord injuries. In: Lin VW, editor. Spinal cord medicine: Principles and practice. New York (NY): Demos Medical Publications; 2002.

11. Washburn RA, Figoni SF. Physical activity and chronic cardiovascular disease prevention in spinal cord injury: A comprehensive literature review. Top Spinal Cord Inj Rehabil. 1998;3:16-32.

12. Nooijen CF, Ter Hoeve N, Field-Fote EC. Gait quality is improved by locomotor training in individuals with SCI regardless of training approach. J Neuroeng Rehabil. 2009; 6(36):36. [PMID: 19799783]

13. Behrman AL, Lawless-Dixon AR, Davis SB, Bowden MG, Nair P, Phadke C, Hannold EM, Plummer P, Harkema SJ. Locomotor training progression and outcomes after incomplete spinal cord injury. Phys Ther. 2005;85(12):1356-71. [PMID: 16305274]

14. Wirz M, Zemon DH, Rupp R, Scheel A, Colombo G, Dietz V, Hornby TG. Effectiveness of automated locomotor training in patients with chronic incomplete spinal cord injury: A multicenter trial. Arch Phys Med Rehabil. 2005;86(4): 672-80. [PMID: 15827916] http://dx.doi.org/10.1016/j.apmr.2004.08.004
15. Gregory CM, Bowden MG, Jayaraman A, Shah P, Behrman A, Kautz SA, Vandenborne K. Resistance training and locomotor recovery after incomplete spinal cord injury: A case series. Spinal Cord. 2007;45(7):522-30.

[PMID: 17228358]

http://dx.doi.org/10.1038/sj.sc.3102002

16. Dobkin B, Barbeau H, Deforge D, Ditunno J, Elashoff R, Apple D, Basso M, Behrman A, Harkema S, Saulino M, Scott M; Spinal Cord Injury Locomotor Trial Group. The evolution of walking-related outcomes over the first 12 weeks of rehabilitation for incomplete traumatic spinal cord injury: The multicenter randomized Spinal Cord Injury Locomotor Trial. Neurorehabil Neural Repair. 2007; 21(1):25-35. [PMID: 17172551]

http://dx.doi.org/10.1177/1545968306295556

17. Jayaraman A, Shah P, Gregory C, Bowden M, Stevens J, Bishop M, Walter G, Behrman A, Vandenborne K. Locomotor training and muscle function after incomplete spinal cord injury: Case series. J Spinal Cord Med. 2008;31(2): 185-93. [PMID: 18581666]

18. Bjornson KF, Belza B, Kartin D, Logsdon R, McLaughlin JF. Ambulatory physical activity performance in youth with cerebral palsy and youth who are developing typically. Phys Ther. 2007;87(3):248-57. [PMID: 17244693] http://dx.doi.org/10.2522/ptj.20060157

19. Elsworth C, Dawes H, Winward C, Howells K, Collett J, Dennis A, Sackley C, Wade D. Pedometer step counts in individuals with neurological conditions. Clin Rehabil. 2009; 23(2):171-75. [PMID: 19164404] http://dx.doi.org/10.1177/0269215508098895

20. Tudor-Locke C, Washington TL, Hart TL. Expected values for steps/day in special populations. Prev Med. 2009;49(1): 3-11. [PMID: 19409409]

http://dx.doi.org/10.1016/j.ypmed.2009.04.012

21. Tudor-Locke C, Burkett L, Reis JP, Ainsworth BE, Macera CA, Wilson DK. How many days of pedometer monitoring predict weekly physical activity in adults? Prev Med. 2005; 40(3):293-98. [PMID: 15533542]

http://dx.doi.org/10.1016/j.ypmed.2004.06.003

22. Baranowski T, Mâsse LC, Ragan B, Welk G. How many days was that? We're still not sure, but we're asking the question better! Med Sci Sports Exerc. 2008;40(7 Suppl): S544-49. [PMID: 18562972] http://dx.doi.org/10.1249/MSS.0b013e31817c6651

23. Ragan BG, Kang M. Reliability: Current issues and concerns. Athl Ther Today. 2005;10(6):35-38.

24. Morrow JR Jr. Generalizability theory. In: Safrit MJ, Woods TM, editors. Measurement concepts in physical education and exercise science. Champaign (IL): Human Kinetics; 1989. p. 77-96. 
25. Wickel EE, Welk GJ. Applying generalizability theory to estimate habitual activity levels. Med Sci Sports Exerc. 2010;42(8):1528-34. [PMID: 20139788]

26. Welk GJ, Schaben JA, Morrow JR Jr. Reliability of accelerometry-based activity monitors: A generalizability study. Med Sci Sports Exerc. 2004;36(9):1637-45. [PMID: 15354049]

27. Matthews CE, Ainsworth BE, Thompson RW, Bassett DR Jr. Sources of variance in daily physical activity levels as measured by an accelerometer. Med Sci Sports Exerc. 2002;34(8):1376-81. [PMID: 12165695] http://dx.doi.org/10.1097/00005768-200208000-00021

28. Coleman KL, Smith DG, Boone DA, Joseph AW, Del Aguila MA. Step activity monitor: Long-term, continuous recording of ambulatory function. J Rehabil Res Dev. 1999; 36(1):8-18. [PMID: 10659890]

29. Shepherd EF, Toloza E, McClung CD, Schmalzried TP. Step activity monitor: Increased accuracy in quantifying ambulatory activity. J Orthop Res. 1999;17(5):703-8. [PMID: 10569479] http://dx.doi.org/10.1002/jor.1100170512

30. Bowden MG, Behrman AL. Step activity monitor: Accuracy and test-retest reliability in persons with incomplete spinal cord injury. J Rehabil Res Dev. 2007;44(3):355-62. [PMID: 18247232] http://dx.doi.org/10.1682/JRRD.2006.03.0033

31. Macko RF, Haeuber E, Shaughnessy M, Coleman KL, Boone DA, Smith GV, Silver KH. Microprocessor-based ambulatory activity monitoring in stroke patients. Med Sci Sports Exerc. 2002;34(3):394-99. [PMID: 11880800] http://dx.doi.org/10.1097/00005768-200203000-00002

32. Crick JE, Brennan RL. Manual for GENOVA: A generalized analysis of variance system. Iowa City (IA): The American College Testing Program; 1983.

33. Vissers M, Van den Berg-Emons R, Sluis T, Bergen M, Stam H, Bussmann H. Barriers to and facilitators of everyday physical activity in persons with a spinal cord injury after discharge from the rehabilitation centre. J Rehabil
Med. 2008;40(6):461-67. [PMID: 18509562]

http://dx.doi.org/10.2340/16501977-0191

34. Wahman K, Biguet G, Levi R. What promotes physical activity after spinal cord injury? An interview study from a patient perspective. Disabil Rehabil. 2006;28(8):481-88. http://dx.doi.org/10.1080/09638280500211932

35. Odom LR, Morrow JR. What's this r? A correlational approach to explaining validity, reliability and objectivity coefficients. Measure Phys Ed Exerc Sci. 2006;10(2):137-45.

36. Kang M, Bassett DR, Barreira TV, Tudor-Locke C, Ainsworth B, Reis JP, Strath S, Swartz A. How many days are enough? A study of 365 days of pedometer monitoring. Res Q Exerc Sport. 2009;80(3):445-53. [PMID: 19791630]

37. Hannold EM, Young ME, Rittman MR, Bowden MG, Behrman AL. Locomotor training: Experiencing the changing body. J Rehabil Res Dev. 2006;43(7):905-16.

[PMID: 17436176

http://dx.doi.org/10.1682/JRRD.2005.07.0122

Submitted for publication September 28, 2010. Accepted in revised form April 20, 2011.

This article and any supplementary material should be cited as follows:

Ishikawa S, Stevens SL, Kang M, Morgan DW. Reliability of daily step activity monitoring in adults with incomplete spinal cord injury. J Rehabil Res Dev. 2011;48(10): 1187-94.

DOI:10.1682/JRRD.2010.09.0190

ResearcherID: Saori Ishikawa, MS, ATC, CSCS: F-69532011

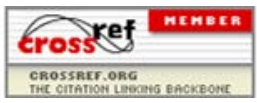

